\title{
Etidronic Acid
}

National Cancer Institute

\section{Source}

National Cancer Institute. Etidronic Acid. NCI Thesaurus. Code C1332.

As a member of the family of drugs known as bisphosphonates, etidronate differs from endogenous pyrophosphate in its resistance to enzymatic hydrolysis. This agent adsorbs to hydroxyapatite cells and reduces the number of osteoclasts, thereby inhibiting abnormal bone resorption. Etidronate may also directly stimulate bone formation by osteoblasts. $(\mathrm{NCl})$ 